Lilei Zhang* and Tianyu Mi

\title{
The crystal structure of (E)-3-(furan-2-yl) acrylonitrile, $\mathrm{C}_{7} \mathrm{H}_{5} \mathrm{NO}$
}

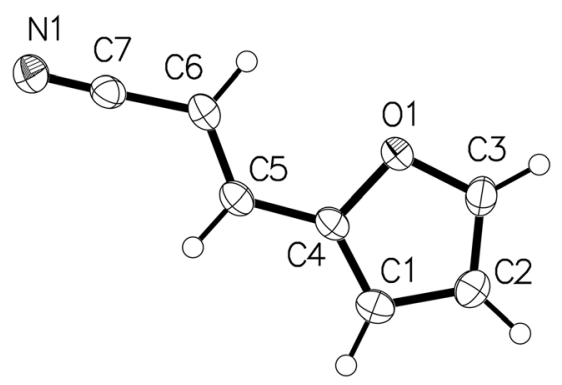

https://doi.org/10.1515/ncrs-2022-0036

Received January 20, 2022; accepted February 21, 2022;

published online March 7, 2022

\section{Abstract}

$\mathrm{C}_{7} \mathrm{H}_{5} \mathrm{NO}$, monoclinic, $P 2_{1} / n$ (no. 14), $a=3.7589(5) \AA$, $b=19.493(2) \AA, c=8.4180(10) \AA, V=601.98(13) \AA^{3}, Z=4$, $R_{g t}(F)=0.0502, w R_{\text {ref }}\left(F^{2}\right)=0.1274, \mathrm{~T}=170 \mathrm{~K}$.

\section{CCDC no.: 2069214}

The molecular structure is shown in Figure. Table 1 contains crystallographic data and Table 2 contains the list of the atoms including atomic coordinates and displacement parameters.

\section{Source of material}

The substrate 2-furanacrylamide $(1.0 \mathrm{mmol})$, (EtO $)_{3} \mathrm{SiH}$ (3.0 mmol), phenylselenophenol iron complex $(2 \mathrm{~mol} \%$ ) as catalyst and tetrahydrofuran (THF) $(2 \mathrm{~mL})$ were added into a $25 \mathrm{~mL}$ Schlenk tube in a nitrogen atmosphere at room temperature. The reaction mixture was stirred at $60^{\circ} \mathrm{C}$ for $24 \mathrm{~h}$. The reaction progress was detected by gas chromatography (GC) and thin layer chromatography (TLC). After the reaction, the product was extracted using petroleum ether $(10 \mathrm{ml})$ three times, and the organic phase were combined together and dried with anhydrous $\mathrm{Na}_{2} \mathrm{SO}_{4}$. The organic solvents were removed by vacuum distillation.

*Corresponding author: Lilei Zhang, College of Chemistry and Chemical Engineering, Luoyang Normal University, 471934, Luoyang, China, E-mail: zhanglilei@outlook.com. https://orcid.org/00000003-0798-1991

Tianyu Mi, College of Chemistry and Chemical Engineering, Luoyang Normal University, 471934, Luoyang, China
Table 1: Data collection and handling.

\begin{tabular}{ll}
\hline Crystal: & Colourless block \\
Size: & $0.15 \times 0.12 \times 0.08 \mathrm{~mm}$ \\
Wavelength: & Mo $K \alpha$ radiation $(0.71073 \AA$ A $)$ \\
$\mu:$ & $0.09 \mathrm{~mm}^{-1}$ \\
Diffractometer, scan mode: & BRUKER APEX-II, $\varphi$ and $\omega$ \\
$\theta_{\text {max }}$, completeness: & $26.5^{\circ},>99 \%$ \\
$N\left(h k l_{\text {measured }}, N\left(h k l l_{\text {unique }}, R_{\text {int }}:\right.\right.$ & $6761,1253,0.075$ \\
Criterion for $I_{\text {obs }}, N(h k l)_{\text {gt }}:$ & $I_{\text {obs }}>2 \sigma\left(I_{\text {obs }}\right), 945$ \\
$N(\text { param })_{\text {refined }}:$ & 82 \\
Programs: & BRUKER $[1]$, OLEX2 [2], SHELX $[3,4]$ \\
\hline
\end{tabular}

Table 2: Fractional atomic coordinates and isotropic or equivalent isotropic displacement parameters $\left(\AA^{2}\right)$.

\begin{tabular}{lrrrr}
\hline Atom & $\boldsymbol{x}$ & $\boldsymbol{y}$ & $\boldsymbol{z}$ & $\boldsymbol{U}_{\text {iso }} \boldsymbol{U}_{\text {eq }}$ \\
\hline C1 & $0.3952(5)$ & $0.68836(10)$ & $0.7127(2)$ & $0.0279(5)$ \\
H1 & 0.380367 & 0.709650 & 0.812593 & $0.033^{*}$ \\
C2 & $0.4694(5)$ & $0.72158(10)$ & $0.5732(2)$ & $0.0290(5)$ \\
H2 & 0.513857 & 0.769072 & 0.561137 & $0.035^{*}$ \\
C3 & $0.4638(6)$ & $0.67189(10)$ & $0.4615(2)$ & $0.0299(5)$ \\
H3 & 0.504792 & 0.679362 & 0.355424 & $0.036^{*}$ \\
C4 & $0.3496(5)$ & $0.62080(10)$ & $0.6770(2)$ & $0.0242(5)$ \\
C5 & $0.2630(5)$ & $0.56344(10)$ & $0.7672(2)$ & $0.0249(5)$ \\
H5 & 0.217764 & 0.572413 & 0.871981 & $0.030^{*}$ \\
C6 & $0.2400(5)$ & $0.49831(10)$ & $0.7170(2)$ & $0.0267(5)$ \\
H6 & 0.288485 & 0.487902 & 0.613531 & $0.032^{*}$ \\
C7 & $0.1454(5)$ & $0.44370(10)$ & $0.8131(2)$ & $0.0266(5)$ \\
N1 & $0.0695(5)$ & $0.39881(9)$ & $0.8877(2)$ & $0.0326(5)$ \\
01 & $0.3916(4)$ & $0.60939(7)$ & $0.52050(15)$ & $0.0281(4)$ \\
\hline
\end{tabular}

Crude products were purified by gel column chromatography and finally recrystallized to obtain the title compound.

\section{Experimental details}

All hydrogen atoms were placed in calculated positions and refined as riding atoms. The $U_{\text {iso }}$ values were constrained to be $1.2 U_{\text {eq. }}$. All the $\mathrm{H}$ atoms were refined as riding on their parent atom.

\section{Comment}

Furan derivatives have a unique status and important feature in a variety of natural products $[5,6]$. They are widely 
used in some important commercial products, like dyes, essential oils, cosmetic, industrial preservative, bioregulators, photosensitizers, fire retardants, and flavoring compounds [7-10]. Additionally, furan analogues show abundant pharmacological properties, like anti-depressant, anti-inflammatory, anti-hypertensive, anti-ageing, anticancer, anti-ulcer, anti-oxidation, and anti-glaucoma effects [11-16], which engage the attention of medicinal chemists to synthesize a series of furan-based derivatives [5]. For example, furan-2-carboxamide and 2-furyl acetonitrile derivatives $[6,17]$ have found use as key intermediates to synthesize new candidates for anti-cancer drugs.

The asymmetric unit of the title structure contains one molecule (see the Figure). Weak intermolecular $\mathrm{C}-\mathrm{H} \cdots \mathrm{O}$ and $\mathrm{C}-\mathrm{H} \cdots \mathrm{N}$ hydrogen bonds are observed. Additionally, a weak intramolecular hydrogen $\mathrm{C} 6-\mathrm{H} 6 \cdots 01$ bond interaction is also formed between $\mathrm{O} 1$ and $\mathrm{H} 6$ atoms. The $\mathrm{C} 7-\mathrm{N} 1$ distance is $1.149(3) \AA$, which indicates a C-N triple bond. The three N1-C7-C6 atoms with the bond angle of 178.5(3) ${ }^{\circ}$ are almost in a straight line. Weak hydrogen bond interactions connect the molecular structures into a threedimensional network. For example, there is a weak C$\mathrm{H}$... O interaction (2.6282(15) $\AA$ ) between $\mathrm{H} 6$ atom and the $\mathrm{O} 1 \mathrm{atom}$ of the adjacent molecule. The similar intermolecular interaction $(\mathrm{C}-\mathrm{H} \cdots \mathrm{N}, 2.5958(18) \AA$ ) was observed in the $\mathrm{H} 2$ and $\mathrm{N} 1$ atoms. All geometric parameters are as expected [18].

Acknowledgements: We gratefully acknowledge support by the key scientific research projects of colleges and universities in Henan Province for financial support (22A430032).

Author contributions: All the authors have accepted responsibility for the entire content of this submitted manuscript and approved submission.

Research funding: Key Scientific Research Projects of Colleges and Universities in Henan Province for financial support (22A430032).

Conflict of interest statement: The authors declare no conflicts of interest regarding this article.

\section{References}

1. Bruker. SMART APEX-II CCD; Bruker AXS Inc.: Madison, WI, USA, 2006.

2. Dolomanov O. V., Bourhis L. J., Gildea R. J., Howard J. A. K., Puschmann H. OLEX2: a complete structure solution, refinement and analysis program. J. Appl. Crystallogr. 2009, 42, 339-341.

3. Sheldrick G. M. Crystal structure refinement with SHELXL. Acta Crystallogr. 2015, C71, 3-8.
4. Sheldrick G. M. SHELXTL - integrated space-group and crystalstructure determination. Acta Crystallogr. 2015, A71, 3-8.

5. Banerjee R., Hks K., Banerjee M. Medicinal significance of furan derivatives: a review. Int. J. Res. Phytochem. Pharm. 2015, 5, 48-57.

6. Mouradzadegun A., Abadast F. Thermally-induced ring contraction as a novel and straightforward route for the synthesis of 2-furyl acetonitrile derivatives. Tetrahedron Lett. 2013, 54, 2641-2644.

7. Sayahi M. H., Adib M., Hamooleh Z., Zhu L., Amanlou M. Reaction between furan- or thiophene-2-carbonyl chloride, isocyanides, and dialkyl acetylenedicarboxy-lates: multicomponent synthesis of 2,2'-bifurans and 2-(thiophen-2-yl)furans. Helv. Chim. Acta 2015, 98, 1231-1239.

8. Rahmati A., Pashmforoush N. Synthesis of various heterocyclic compounds via multi-component reactions in water.J. Iran. Chem. Soc. 2015, 12, 993-1036.

9. Al-Fakih A. M., Aziz M., Abdallah H. H., Algamal Z. Y., Lee M. H., Maarof $\mathrm{H}$. High dimensional QSAR study of mild steel corrosion inhibition in acidic medium by furan derivatives. Int. J. Electrochem. Sci. 2015, 10, 3568-3583.

10. Santonicola S., Mercogliano R. Occurrence and production of furan in commercial foods. Ital. J. Food Sci. 2016, 28, 155.

11. de Paulis T Drug evaluation: vilazodone-a combined SSRI and 5-HT1A partial agonist for the treatment of depression. IDrugs 2007, 10, 193-201.

12. Viola G., Vedaldi D., dall'Acqua F., Basso G., Disarò S., Spinelli M., Cosimelli B., Boccalini M., Chimichi S. Synthesis, cytotoxicity, and apoptosis induction in human tumor cells by geiparvarin analogues. Chem. Diodivers. 2004, 1, 1265-1280.

13. Hodgson R. A., Bertorelli R., Varty G. B., Lachowicz J. E., Forlani A., Fredduzzi S., Cohen-Williams M. E., Higgins G. A., Impagnatiello F., Nicolussi E. Characterization of the potent and highly selective A2A receptor antagonists preladenant and SCH 412348 [7-[2-[42,4-difluorophenyl]- 1-piperazinyl]ethyl]-2-(2-furanyl)-7 $\mathrm{H}$ pyrazolo[4,3-e][1,2,4] triazolo[1,5-c]pyrimidin-5-amine] in rodent models of movement disorders and depression. J. Pharmacol. Exp. Therapeut. 2009, 330, 294-303.

14. Shwetha B., Sudhanva M. S., Jagadeesha G. S., Thimmegowda N. R., Hamse V. K., Sridhar B. T., Thimmaiah K. N., Ananda Kumar C. S., Shobith R., Rangappa K. S. Furan-2-carboxamide derivative, a novel microtubule stabilizing agent induces mitotic arrest and potentiates apoptosis in cancer cells. Bioorg. Chem. 2021, 108, 104586.

15. Kumar N., Gusain A., Kumar J., Singh R., Hota P. K. Anti-oxidation properties of 2-substituted furan derivatives: a mechanistic study. J. Lumin. 2021, 230, 117725.

16. Alizadeh M., Jalal M., Hamed K., Saber A., Kheirouri S., Pourteymour F., Kamari N. Recent updates on anti-inflammatory and antimicrobial effects of furan natural derivatives. J. Inflamm. Res. 2020, 13, 451-463.

17. Shwetha B., Sudhanva M. S., Jagadeesha G. S., Thimmegowda N. R., Hamse V. K., Sridhar B. T., Thimmaiah K. N., Ananda Kumar C. S., Shobith R., Rangappa K. S. Furan-2-carboxamide derivative, a novel microtubule stabilizing agent induces mitotic arrest and potentiates apoptosis in cancer cells. Bioorg. Chem. 2021, 108, 104586.

18. Pomes Hernandez R., Duque Rodriguez J., Villena Rodriguez R., Soriano Garcia M. Two cyanacrylamides. Acta Crystallogr. 1995 , C51, 1575-1577. 